\title{
Basilar invagination in headache associated with physical exertion and recurrent torticollis
}

Invaginação basilar em cefaleia associada ao esforço físico e torcicolo recorrente Paulo Victor Sgobbi de Souza ${ }^{1}$, Wladimir Bocca Vieira de Rezende Pinto², Acary Souza Bulle Oliveira ${ }^{2}$

A 52-year-old man presented with a 2-year-history of recurrent torticollis and headache associated with physical exertion (including evacuation). His physical examination disclosed short neck and brachycephaly. Neuroimaging studies (Figures 1 and 2) revealed basilar invagination and brainstem compression with- out other craniocervical junction abnormalities or systemic diseases. Basilar invagination ${ }^{1}$ must be included in the differential diagnosis of exercise-induced headache with recurrent torticollis ${ }^{2}$, especially if pyramidal signs, ataxia or other cranio-vertebral anomalies in the neuraxis are present $t^{1,3}$.
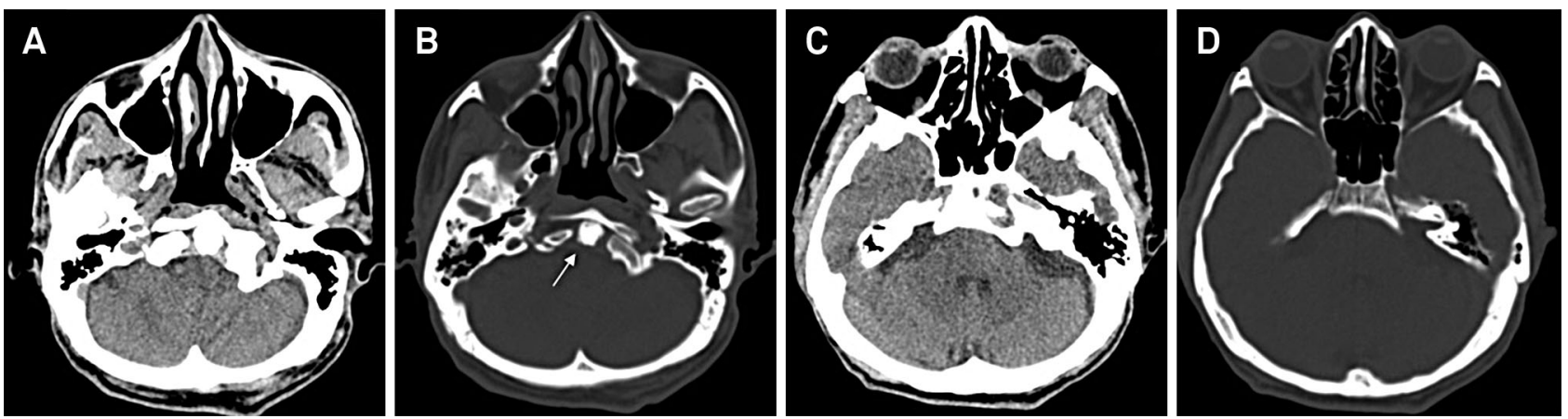

Figure 1. (A-D) Noncontrast cranial CT axial slices showing a higher position of the odontoid (white arrow).
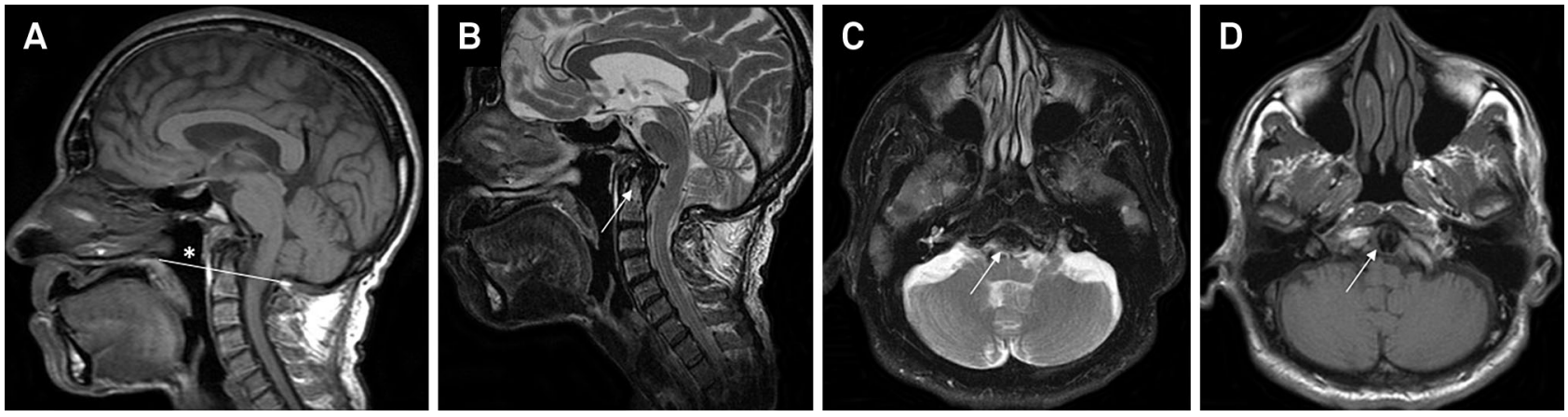

Figure 2. (A) T1-weighted and (B) T2-weighted midsagittal MR images showing important compression of the brainstem and medulla oblongata and a higher position of the tip of the odontoid process with a greater extension than $5 \mathrm{~mm}$ above the Chamberlain line (white asterisk, white line); (C) T2-weighted and (D) T1-weighted axial MR images unvealing ventral compression of medulla oblongata (odontoid process shown by white arrow).

\footnotetext{
${ }^{1}$ Universidade Federal de São Paulo, Sao Paulo SP, Brazil;

${ }^{2}$ Departamento de Neurologia e Neurocirurgia, Universidade Federal de São Paulo, Sao Paulo SP, Brazil. Toledo,650; 04023-900 São Paulo SP, Brasil; E-mail: wladimirbvrpinto@gmail.com

Conflict of interest: There is no conflict of interest to declare.

Received 27 February 2014; Received in final form 14 August 2014; Accepted 02 September 2014.
}

Correspondence: Wladimir Bocca Vieira de Rezende Pinto; Departamento de Neurologia e Neurocirurgia, Universidade Federal de São Paulo; Rua Pedro de 
1. Smith JS, Shaffrey $\mathrm{Cl}$, Abel MF, Menezes AH. Basilar invagination. Neurosurgery. 2010;66(3 Suppl):39-47. http://dx.doi.org/10.1227/01. NEU.0000365770.10690.6F

2. Queiroz LP. Symptoms and therapies: exertional and sexual headaches. Curr Pain Headache Rep. 2001;5(3):275-8. http://dx.doi.org/ 10.1007/s11916-001-0042-x
3.

Goel A. Basilar invagination, Chiari malformation, syringomyelia: a review. Neurol India. 2009;57(3):235-46. http://dx.doi.org/10.4103/ 0028-3886.53260 